\title{
Recovery From COVID-19 in Multiple Sclerosis
}

\section{A Prospective and Longitudinal Cohort Study of the United Kingdom Multiple Sclerosis}

\section{Register}

Afagh Garjani, MD, Rodden M. Middleton, MBA, Richard Nicholas, FRCP, and Nikos Evangelou, FRCP

Neurol Neuroimmunol Neuroinflamm 2022;9:e1118. doi:10.1212/NXI.0000000000001118

\section{Abstract}

\section{Background and Objectives}

To understand the course of recovery from coronavirus disease 2019 (COVID-19) among patients with multiple sclerosis (MS) and to determine its predictors, including patients' pre-COVID-19 physical and mental health status.

\section{Methods}

This prospective and longitudinal cohort study recruited patients with MS who reported COVID-19 from March 17, 2020, to March 19, 2021, as part of the United Kingdom MS Register (UKMSR) COVID-19 study. Participants used online questionnaires to regularly update their COVID-19 symptoms, recovery status, and duration of symptoms for those who fully recovered. Questionnaires were date stamped for estimation of COVID-19 symptom duration for those who had not recovered at their last follow-up. The UKMSR holds demographic and up-to-date clinical data on participants as well as their web-based Expanded Disability Status Scale (web-EDSS) and Hospital Anxiety and Depression Scale (HADS) scores. The association between these factors and recovery from COVID-19 was assessed using multivariable Cox regression analysis.

\section{Results}

Of the 7,977 patients with MS who participated in the UKMSR COVID-19 study, 599 reported COVID-19 and prospectively updated their recovery status. Twenty-eight hospitalized participants were excluded. At least 165 participants (29.7\%) had long-standing COVID-19 symptoms for $\geq 4$ weeks and 69 (12.4\%) for $\geq 12$ weeks. Participants with pre-COVID-19 webEDSS scores $\geq 7$, participants with probable anxiety and/or depression (HADS scores $\geq 11$ ) before COVID-19 onset, and women were less likely to report recovery from COVID-19.

\section{Discussion}

Patients with MS are affected by postacute sequelae of COVID-19. Preexisting severe neurologic impairment or mental health problems appear to increase this risk. These findings can have implications in tailoring their post-COVID-19 rehabilitation.

\author{
Correspondence \\ Dr. Evangelou \\ nikos.evangelou@nottingham.ac.uk
}

\section{MORE ONLINE}

COVID-19 Resources

For the latest articles, invited commentaries, and blogs from physicians around the world NPub.org/COVID19 


\section{Glossary}

COVID-19 = coronavirus disease 2019; HADS $=$ Hospital Anxiety and Depression Scale; IQR = interquartile range; MS = multiple sclerosis; PASC = postacute sequelae of COVID-19; web-EDSS = web-based Expanded Disability Status Scale; UKMSR = United Kingdom MS Register.

Many patients with multiple sclerosis (MS) evade the serious acute complications of coronavirus disease 2019 (COVID19), such as hospitalization, respiratory failure, or death. ${ }^{1,2}$ Nevertheless, they may still have long-term effects of the infection, known as postacute sequelae of COVID-19 (PASC).

Understanding the burden of PASC among patients with MS and identifying its risk factors will inform MS rehabilitation services, which are going to deal with the emerging needs of patients with MS who had COVID-19. In this study, we aim to understand the course of recovery from COVID-19 in MS and to determine its predictors.

\section{Methods}

This prospective and longitudinal cohort study was conducted as part of the United Kingdom MS Register (UKMSR) COVID-19 study. ${ }^{2}$ Patients with MS had been reporting whether they had symptoms suggestive of COVID-19 and whether their diagnosis was confirmed by a health care provider or COVID-19 testing, from March 17, 2020 — the start of the outbreak in the United Kingdom. ${ }^{2}$ Further information about COVID-19 testing was not collected, but, in the United Kingdom, patients with COVID-19 symptoms are only offered a PCR test. Mass COVID-19 testing in the United Kingdom was implemented on May 28, 2020-before then, PCR tests were only available to inpatients. All data were collected using online questionnaires.

Patients with MS with self-reported symptoms suggestive of COVID-19 were included in the study. They were followed up, by email reminders, every 2 weeks to update their COVID-19 symptoms and recovery status until reporting full recovery from COVID-19 symptoms (questions provided in eAppendix 1, links.lww.com/NXI/A670). Participants who reported full recovery also provided the duration of their COVID-19 symptoms. The submitted questionnaires were date stamped for estimation of COVID-19 symptom duration for participants who had not reported full recovery at their last follow-up. Participants were asked to specifically report new or worsened symptoms after their COVID-19.

The UKMSR holds demographic and up-to-date clinical data on registered patients, including comorbidities, MS type, date of MS diagnosis, disease-modifying therapies, web-based Expanded Disability Status Scale (web-EDSS) scores, and Hospital Anxiety and Depression Scale (HADS) scores. The most recent web-EDSS and HADS scores before COVID-19 onset were used.
Participants were grouped into 5 groups based on their webEDSS score: (1) 0-2.5 (ambulatory without assistance and no or minimal neurologic impairment); (2) 3-3.5 (ambulatory without assistance and moderate neurologic impairment); (3) 4-5.5 (ambulatory without assistance and severe neurologic impairment); (4) 6-6.5 (ambulatory with assistance), and (5) $\geq 7$ (restricted to wheelchair or bed).

HADS is scored (0-21) for anxiety and depression separately. Participants with HADS scores of $\geq 11$ were considered as having probable anxiety or depression. ${ }^{3}$ Participants with anxiety, depression, or both were considered as 1 group because these conditions frequently coexist in $\mathrm{MS},{ }^{4}$ and the number of participants with anxiety or depression alone was small. Data collected until March 19, 2021, are presented according to STROBE guidelines. ${ }^{5}$

\section{Standard Protocol Approvals, Registrations, and Patient Consents}

Ethical approval for UKMSR studies was obtained from Southwest-Central Bristol Research Ethics Committee (16/ SW/0194). All participants provided informed consent online. The study is registered with ClinicalTrials.gov (NCT04354519).

\section{Statistical Analysis}

Data were analyzed using IBM SPSS Statistics for Windows, version 26 (IBM Corp., Armonk, NY; 2019).

Continuous variables with normal distribution are presented as mean (SD) and were compared using the independent samples $t$ test. Continuous variables without normal distribution and ordinal variables are presented as median (interquartile range $[\mathrm{IQR}])$ and were compared using the Mann-Whitney $U$ test. The association between categorical variables was assessed using the $\chi^{2}$ test or the Fisher exact test. The number of valid values for variables with missing data has been stated.

Univariable and multivariable Cox regression analyses, with time (days) from reporting COVID-19 to full recovery (event) as the dependent variable, were performed to assess the association between demographic and clinical variables and recovery from COVID-19. Participants with persistent symptoms at their last follow-up were censored. A directed acyclic graph was produced (eAppendix 2, links. lww.com/NXI/A670) to identify potential confounding factors, which were subsequently accounted for in the multivariable Cox regression analysis. This method avoids the introduction of bias in the analysis by the erroneous inclusion of colliders and mediators as confounding factors. ${ }^{6}$ Listwise deletion was implemented for missing data. 
Table 1 Characteristics of Patients With MS and COVID-19 in Relation to the Duration of Their COVID-19 Symptoms

\begin{tabular}{|c|c|c|c|}
\hline & $\begin{array}{l}<4 \text { wk } \\
n=371\end{array}$ & $\begin{array}{l}\geq 4 w^{a} \\
n=165\end{array}$ & $\begin{array}{l}\geq 12 \mathrm{wk} \\
n=69\end{array}$ \\
\hline Age, mean (SD), y & $49(11)$ & $50(11)$ & $51(11)$ \\
\hline Women, no. (\%) & $275(74.1)$ & $136(82.4)$ * & $59(85.5)^{\star}$ \\
\hline White ethnicity, no. (\%) & $350(94.3)$ & $157(95.2)$ & $68(98.6)$ \\
\hline Comorbidities $^{\text {b }}$, no. (\%) & $\mathrm{n}=295$ & $\mathrm{n}=125$ & $n=53$ \\
\hline Diabetes & $12(4.1)$ & $3(2.4)$ & $2(3.8)$ \\
\hline Heart disease & $6(2)$ & $1(0.8)$ & $0(0)$ \\
\hline Hyperlipidemia & $21(7.1)$ & $5(4)$ & $5(9.4)$ \\
\hline Hypertension & $32(10.8)$ & $13(10.4)$ & $7(13.2)$ \\
\hline Peripheral vascular disease & $1(0.3)$ & $0(0)$ & $0(0)$ \\
\hline Kidney disease & $3(1)$ & $3(2.4)$ & $0(0)$ \\
\hline Liver disease & $1(0.3)$ & $0(0)$ & $0(0)$ \\
\hline Lung disease & $30(10.2)$ & $18(14.4)$ & $10(18.9)$ \\
\hline Anxiety and/or depression ${ }^{c}$ & $80 / 252(31.7)$ & $57 / 113(50.4) * *$ & $25 / 46(54.3)$ * \\
\hline Web-EDSS score ${ }^{\mathrm{b}}$, median (IQR) & $4(2.625-6.5) n=264$ & $5(3-6.5) n=113$ & $5.5(4-6.5) *_{n}=50$ \\
\hline Web-EDSS score $=0-2.5$, no. $(\%)$ & $66(25)$ & $23(20.4)$ & $7(14)$ \\
\hline Web-EDSS score = 3-3.5, no. (\%) & $45(17)$ & $11(9.7)$ & $4(8)$ \\
\hline Web-EDSS score = 4-5.5, no. (\%) & $69(26.1)$ & $32(28.3)$ & $15(30)$ \\
\hline Web-EDSS score = 6-6.5, no. (\%) & $53(20.1)$ & $31(27.4)$ & $15(30)$ \\
\hline Web-EDSS score $\geq 7$, no. (\%) & $31(11.7)$ & $16(14.2)$ & $9(18)$ \\
\hline MS disease duration, median (IQR), y & $10(5-17) n=359$ & $11(5.25-19) n=160$ & $13(6.25-19) n=68$ \\
\hline \multicolumn{4}{|l|}{ Type of MS, no. (\%) } \\
\hline RRMS & $265(71.4)$ & $114(69.1)$ & $48(69.6)$ \\
\hline SPMS & $65(17.5)$ & $33(20)$ & $15(21.7)$ \\
\hline PPMS & $24(6.5)$ & $10(6.1)$ & $5(7.2)$ \\
\hline Unknown & $17(4.6)$ & $8(4.8)$ & $1(1.4)$ \\
\hline Taking a DMT, no. (\%) & $188(50.7)$ & $84(50.9)$ & $32(46.4)$ \\
\hline Alemtuzumab & $14(3.8)$ & $4(2.4)$ & $2(2.9)$ \\
\hline Beta interferons & $31(8.4)$ & $5(3)$ & $2(2.9)$ \\
\hline Cladribine & $8(2.2)$ & $3(1.8)$ & $0(0)$ \\
\hline Dimethyl fumarate & $49(13.2)$ & $25(15.2)$ & $10(14.5)$ \\
\hline Fingolimod & $22(5.9)$ & $11(6.7)$ & $3(4.3)$ \\
\hline Glatiramer acetate & $16(4.3)$ & $12(7.3)$ & $7(10.1)$ \\
\hline Natalizumab & $23(6.2)$ & $10(6.1)$ & $4(5.8)$ \\
\hline Ocrelizumab & $15(4)$ & $8(4.8)$ & $3(4.3)$ \\
\hline Rituximab & $0(0)$ & $2(1.2)$ & $1(1.4)$ \\
\hline Siponimod & $1(0.3)$ & $0(0)$ & $0(0)$ \\
\hline Teriflunomide & $8(2.2)$ & $3(1.8)$ & $0(0)$ \\
\hline
\end{tabular}


Table 1 Characteristics of Patients With MS and COVID-19 in Relation to the Duration of Their COVID-19 Symptoms (continued)

\begin{tabular}{llll}
\hline & $\begin{array}{l}<\mathbf{w k} \\
\mathbf{n}=\mathbf{3 7 1}\end{array}$ & $\begin{array}{l}\mathbf{2} \mathbf{w k} \\
\mathbf{n}=\mathbf{1 6 5}\end{array}$ & $\begin{array}{l}\mathbf{1 2} \mathbf{w k} \\
\mathbf{n}=\mathbf{6 9}\end{array}$ \\
\hline Other & $1(0.3)$ & $1(0.6)$ & $0(0)$ \\
\hline
\end{tabular}

Abbreviations: COVID-19 = coronavirus disease 2019; DMT = disease-modifying therapy; IQR = interquartile range; MS = multiple sclerosis; PPMS = primary progressive multiple sclerosis; RRMS = relapsing-remitting multiple sclerosis; SPMS = secondary progressive multiple sclerosis; web-EDSS = web-based Expanded Disability Status Scale.

${ }^{\star} p<0.05$ and $* \star p=0.001$. Comparisons were made to participants with symptom duration of $<4$ wk.

a Includes participants with COVID-19 symptoms for $\geq 12$ weeks.

b Before COVID-19 onset.

c Participants with Hospital Anxiety and Depression Scale scores $\geq 11$ for anxiety or depression were considered as having probable anxiety or depression, respectively.

Results are presented as adjusted hazard ratios with $95 \%$ confidence intervals.

\section{Data Availability}

Data are stored on the UKMSR Secure e-Research Platform at Swansea University Medical School. Line level data cannot be released, but qualified researchers, subject to governance, can request access to data.

\section{Results}

Of the 7,977 patients with MS who participated in the UKMSR COVID-19 study, 1,096 reported COVID-19. A total of 599 patients with MS and COVID-19 updated their recovery status (participants), and 497 did not (nonparticipants). Twenty-eight participants $(4.7 \%)$ and $8(1.6 \%)$ nonparticipants were hospitalized during their acute infection $(p=0.05)$. Only 16

Table 2 Results of the Multivariable Cox Regression Analysis ${ }^{a}$ of Pre-COVID-19 Factors Associated With Recovery From COVID-19

\begin{tabular}{|c|c|c|c|c|c|c|}
\hline & $\begin{array}{l}\text { Included in } \\
\text { the analysis, no. }\end{array}$ & $\begin{array}{l}\text { Censored, } \\
\text { no. }\end{array}$ & aHR & $\begin{array}{l}\text { Lower } \\
95 \% \mathrm{Cl}\end{array}$ & $\begin{array}{l}\text { Upper } \\
95 \% \mathrm{Cl}\end{array}$ & Adjustments \\
\hline Age (1-y increment) & 556 & 115 & 0.996 & 0.988 & 1.005 & None \\
\hline Women vs men & 556 & 115 & 0.756 & 0.609 & 0.937 & None \\
\hline All other ethnicities vs White ethnicity & 556 & 115 & 1.374 & 0.937 & 2.016 & None \\
\hline MS disease duration (1-y increment) & 538 & 112 & 0.995 & 0.983 & 1.008 & Age \\
\hline Anxiety and/or depression ${ }^{b, c}$ & 314 & 65 & 0.708 & 0.533 & 0.941 & Age, Gender, Ethnicity, Web-EDSS categories \\
\hline Web-EDSS ${ }^{c}$ & 380 & 74 & - & - & - & Age, Gender, MS disease duration, MS type \\
\hline Score $=0-2.5$ (reference) & - & - & 1 & 1 & 1 & \\
\hline Score $=3-3.5$ & - & - & 1.123 & 0.783 & 1.610 & \\
\hline Score $=4-5.5$ & - & - & 0.751 & 0.542 & 1.040 & \\
\hline Score $=6-6.5$ & - & - & 0.698 & 0.485 & 1.006 & \\
\hline Score $\geq 7$ & - & - & 0.614 & 0.381 & 0.989 & \\
\hline MS type & 538 & 112 & - & - & - & Age, Gender, MS disease duration \\
\hline RRMS (reference) & - & - & 1 & 1 & 1 & \\
\hline SPMS & - & - & 1.049 & 0.765 & 1.438 & \\
\hline PPMS & - & - & 1.212 & 0.798 & 1.841 & \\
\hline Taking a DMT & 556 & 115 & 0.985 & 0.788 & 1.232 & Age, MS type \\
\hline
\end{tabular}

Abbreviations: 95\% Cl = 95\% confidence interval; aHR = adjusted hazard ratio; COVID-19 = coronavirus disease 2019; DMT = disease-modifying therapy; MS = multiple sclerosis; PPMS = primary progressive multiple sclerosis; RRMS = relapsing-remitting multiple sclerosis; SPMS = secondary progressive multiple sclerosis; Web-EDSS = web-based Expanded Disability Status Scale.

Bold indicates statistically significant findings.

a Results of the univariable Cox Regression analysis are provided in eTable 2, links.Iww.com/NXI/A670.

b Participants with Hospital Anxiety and Depression Scale scores $\geq 11$ for anxiety or depression were considered as having probable anxiety or depression, respectively.

'Before COVID-19 onset. 
Figure Frequency of COVID-19 Symptoms Among Patients With Multiple Sclerosis With Persistent Symptoms at Their Last Follow-up in $\geq 4$ (A) and $\geq 12$ (B) Weeks From Reporting COVID-19
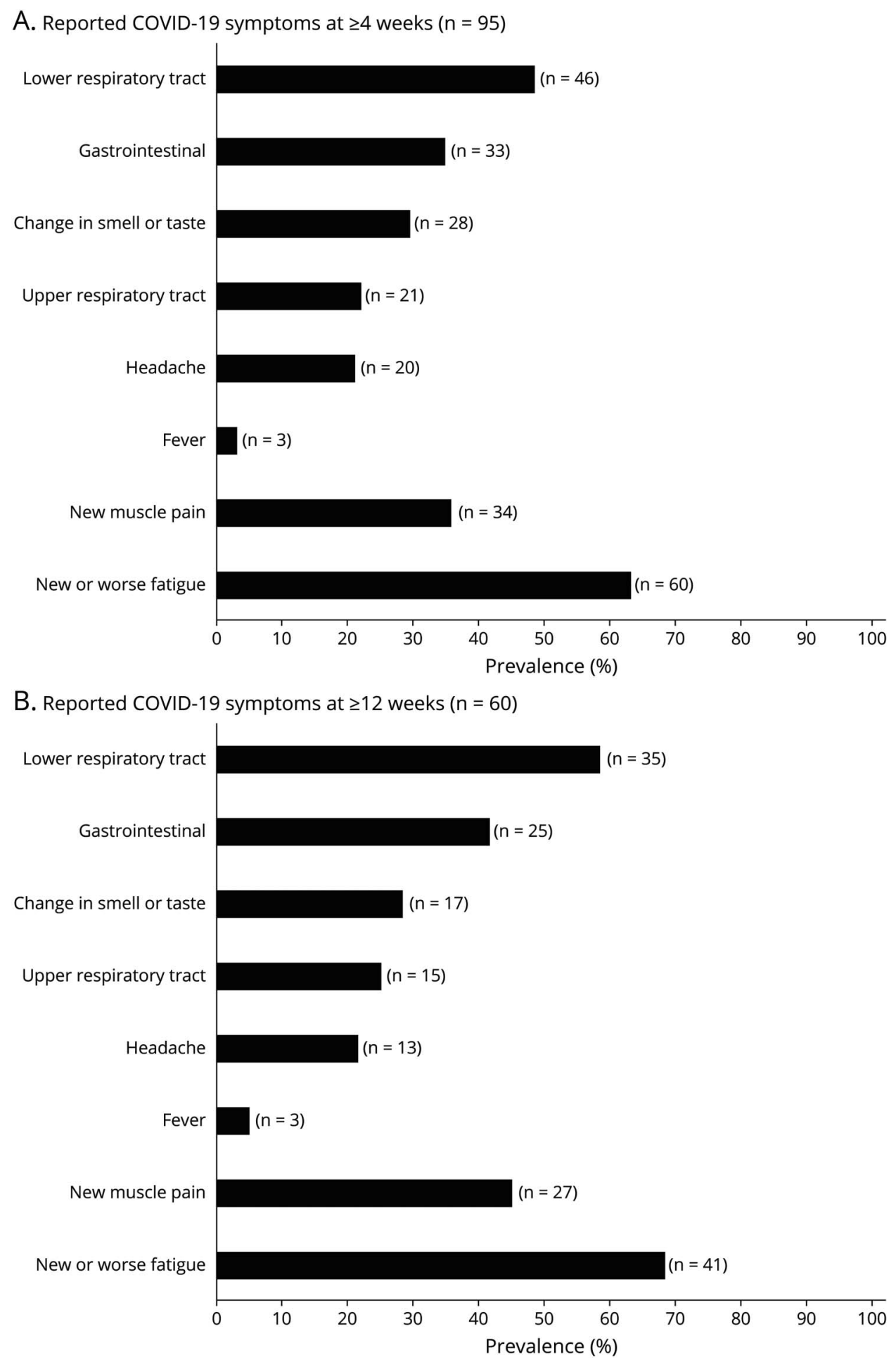

Gastrointestinal symptoms included diarrhea, nausea or vomiting, or stomach pain. Lower respiratory tract symptoms included coughs, shortness of breath, or heaviness in the chest. Upper respiratory tract symptoms included sore throat, nasal congestion, or sneezing. COVID-19= coronavirus disease 2019 .

participants (and all hospitalized nonparticipants) were admitted to hospital because of COVID-19. Therefore, hospitalized patients with MS were excluded from the analysis. Participants did not differ in their baseline characteristics (including demographics, MS type, web-EDSS score, disease-modifying therapies, comorbidities, or having anxiety and/or depression) from nonparticipants, except for a lower rate of hypertension among participants (10.8\%) than nonparticipants (16.3\%) (eTable 1, links.lww.com/NXI/A670).

Four hundred forty-four participants (77.8\%) reported full recovery from COVID-19 at their last follow-up. Their 
median (IQR) symptom duration was 10 (6-21) days ( $\mathrm{n}=$ 441); 70 recovered in $\geq 4$ weeks and 9 in $\geq 12$ weeks. However, 127 participants $(22.2 \%)$ had persistent symptoms at their last follow-up. They had been followed up for a median (IQR) of 87 (41-185) days ( $\mathrm{n}=115)$, with 95 having symptoms for $\geq 4$ weeks and 60 for $\geq 12$ weeks from reporting COVID-19. Therefore, at least 165 participants (29.7\%) had lasting COVID-19 symptoms for $\geq 4$ weeks and 69 (12.4\%) for $\geq 12$ weeks. The characteristics of participants by their symptom duration are compared in Table 1 . A post hoc analysis among participants with a COVID-19 diagnosis confirmed by a health care provider or testing showed similar findings (eAppendix 3, links.lww.com/NXI/A670).

Participants with a pre-COVID-19 web-EDSS score of $\geq 7$, participants with anxiety and/or depression before COVID-19 onset, and women were less likely to report recovery from COVID-19 (Table 2). Of 95 participants who reported their COVID-19 symptoms at $\geq 4$ weeks, 78 (82.1\%) had symptoms, which were not typical for MS (symptoms listed in Figure, except for fatigue and pain). Of 60 participants who reported their symptoms at $\geq 12$ weeks, 50 (83.3\%) had non-MS-related symptoms.

\section{Discussion}

This prospective study of a large national cohort of nonhospitalized patients with MS and COVID-19 shows that about $30 \%$ and $12 \%$ of patients experience prolonged COVID-19 symptoms for $\geq 4$ and $\geq 12$ weeks, respectively. These rates in the MS population are higher than the general population, as reported by a study using a similar methodology (13\% and 2\%, respectively). ${ }^{7}$ Another study reports a much higher prevalence of prolonged COVID-19 in the general population, but its retrospective data collection could have led to recall bias. ${ }^{8}$ Given that MS shares many neurologic symptoms of COVID-19 and that the infection can lead to MS exacerbations, ${ }^{9}$ a high prevalence of long-lasting COVID-19 symptoms in this population may seem expected. More than $80 \%$ of patients with MS with persistent COVID-19 symptoms in the study, however, also had symptoms that were not typical for MS. Further studies using direct control groups, from both the general population and patients with MS without COVID-19, are needed to establish the risk of PASC in MS.

An association between physical disability and adverse acute COVID-19 outcomes in MS has been previously reported. ${ }^{1}$ This study shows that higher levels of pre-COVID-19 neurologic disability predispose patients with MS to long-term sequelae of COVID-19 as well. Other MS-related factors such as disease duration or disease-modifying therapies did not appear to influence recovery from COVID-19. Patients with MS with pre-COVID-19 mental health problems can also be disproportionately affected by PASC, which has also recently been reported in the general population. ${ }^{10}$ The observation that women are more likely to experience prolonged COVID-19 symptoms is in accordance with other studies. ${ }^{\text {? }}$
A limitation of the study is that the COVID-19 diagnosis of patients with MS was confirmed by laboratory testing in only a proportion of participants, as widespread testing was not available in the United Kingdom at the time of recruitment. However, the rates of prolonged COVID-19 in the subgroup with confirmed diagnosis and the total study population were similar. Hospitalized patients with MS were excluded to avoid the potential confounding effect of hospitalization on recovery from COVID-19. The association between hospitalization and COVID-19 recovery could not be assessed because of the small sample size of hospitalized patients with MS and the risk of selection bias toward nonhospitalized patients due to the questionnaire-based nature of the study.

These findings will inform MS and post-COVID-19 rehabilitation services in developing individualized pathways for patients with MS, helping to reduce the burden on these health systems in the COVID-19 era. They also highlight the importance of vaccination against COVID-19 in the MS population who appear to be vulnerable to the long-term effects of infection.

\section{Study Funding}

United Kingdom Multiple Sclerosis Society (Grant no. 131).

\section{Disclosure}

A. Garjani has received research support from the United Kingdom Multiple Sclerosis Society, speaker honorarium from the Multiple Sclerosis Academy, and travel support from Novartis, Merck, and the Multiple Sclerosis Academy. R.M. Middleton has received funding from the United Kingdom Multiple Sclerosis Society. R. Nicholas has received support for advisory boards and travel from Novartis, Roche, and Biogen. He has received grant support from the United Kingdom Multiple Sclerosis Society. He is a member of a National Institute for Health and Care Excellence (NICE) Health Technology Assessment (HTA) committee. N. Evangelou has served as a member of advisory boards for Biogen, Merck, Novartis, and Roche and has received grant income from the United Kingdom Multiple Sclerosis Society, Medical Research Council (MRC), Patient-Centered Outcomes Research Institute (PCORI), and National Institute for Health Research (NIHR). Go to Neurology.org/NN for full disclosures.

\section{Publication History}

Previously published in medRxiv: doi.org/10.1101/2021.06.25. 21259256. Received by Neurology: Neuroimmunology \& Neuroinflammation July 2, 2021. Accepted in final form October 7, 2021.

Appendix Authors

\begin{tabular}{|c|c|c|}
\hline Name & Location & Contribution \\
\hline $\begin{array}{l}\text { Afagh } \\
\text { Garjani, } \\
\text { MD }\end{array}$ & $\begin{array}{l}\text { Mental Health and Clinical } \\
\text { Neurosciences Academic } \\
\text { Unit, School of Medicine, } \\
\text { University of Nottingham, } \\
\text { Nottingham, United } \\
\text { Kingdom; Clinical Neurology, } \\
\text { Nottingham University } \\
\text { Hospitals NHS Trust, } \\
\text { Nottingham, United Kingdom }\end{array}$ & $\begin{array}{l}\text { Drafting/revision of the } \\
\text { manuscript for content, } \\
\text { including medical writing for } \\
\text { content; major role in the } \\
\text { acquisition of data; study } \\
\text { concept or design; and } \\
\text { analysis or interpretation of } \\
\text { data }\end{array}$ \\
\hline
\end{tabular}


Appendix (continued)

\begin{tabular}{lll}
\hline Name & Location & Contribution \\
\hline $\begin{array}{l}\text { Rodden M. } \\
\text { Middleton, } \\
\text { MBA }\end{array}$ & $\begin{array}{l}\text { Population Data Science, } \\
\text { Swansea University Medical } \\
\text { School, Swansea, United } \\
\text { Kingdom }\end{array}$ & $\begin{array}{l}\text { Drafting/revision of the } \\
\text { manuscript for content, } \\
\text { including medical writing for } \\
\text { content; major role in the } \\
\text { acquisition of data; and study } \\
\text { concept or design }\end{array}$ \\
\hline $\begin{array}{l}\text { Richard } \\
\text { Nicholas, }\end{array}$ & $\begin{array}{l}\text { Department of Cellular and } \\
\text { FRCP }\end{array}$ & $\begin{array}{l}\text { Drafting/revision of the } \\
\text { Imperial College London, } \\
\text { London, United Kingdom } \\
\text { including medical writing for } \\
\text { content; major role in the } \\
\text { acquisition of data; study } \\
\text { concept or design; and analysis } \\
\text { or interpretation of data }\end{array}$ \\
\hline $\begin{array}{l}\text { Nikos } \\
\text { Evangelou } \\
\text { FRCP }\end{array}$ & $\begin{array}{l}\text { Mental Health and Clinical } \\
\text { Neurosciences Academic } \\
\text { Unit, School of Medicine, } \\
\text { University of Nottingham, } \\
\text { Nottingham, United } \\
\text { Kingdom; Clinical Neurology, }\end{array}$ & $\begin{array}{l}\text { Drafting/revision of the } \\
\text { manuscript for content, } \\
\text { including medical writing for } \\
\text { content; major role in the } \\
\text { acquisition of data; study } \\
\text { concept or design; and analysis } \\
\text { or interpretation of data }\end{array}$ \\
& $\begin{array}{l}\text { Nottingham University } \\
\text { Hospitals NHS Trust, } \\
\text { Nottingham, United Kingdom }\end{array}$ & \\
\hline & &
\end{tabular}

\section{References}

1. Salter A, Fox RJ, Newsome SD, et al. Outcomes and risk factors associated with SARSCoV-2 infection in a North American Registry of patients with multiple sclerosis. JAMA Neurol. 2021;78(6):699-708.

2. Evangelou N, Garjani A, dasNair R, et al. Self-diagnosed COVID-19 in people with multiple sclerosis: a community-based cohort of the UK MS Register. J Neurol Neurosurg Psychiatry. 2020;92(1):107-109.

3. Marrie RA, Zhang L, Lix LM, et al. The validity and reliability of screening measures for depression and anxiety disorders in multiple sclerosis. Mult Scler Relat Disord. 2018;20:9-15.

4. Wood B, Van Der Mei IA, Ponsonby AL, et al. Prevalence and concurrence of anxiety, depression and fatigue over time in multiple sclerosis. Mult Scler. 2013; $19(2): 217-224$.

5. von Elm E, Altman D, Egger M. On behalf of the Iniciativa STROBE. The strengthening the reporting of observational studies in epidemiology (STROBE) statement: guidelines for reporting observational studies. Ann Intern Med. 2007;147: 573-577.

6. Williams TC, Bach CC, Matthiesen NB, Henriksen TB, Gagliardi L. Directed acyclic graphs: a tool for causal studies in paediatrics. Pediatr Res. 2018;84(4): 487-493.

7. Sudre CH, Murray B, Varsavsky T, et al. Attributes and predictors of long COVID. Nat Med. 2021;27(4):626-631.

8. Whitaker M, Elliott J, Chadeau-Hyam M, et al. Persistent Symptoms Following SARSCoV-2 Infection in a Random Community Sample of 508,707 People [online]. Accessed July 1, 2021. hdl.handle.net/10044/1/89844.

9. Garjani A, Middleton RM, Hunter R, et al. COVID-19 is associated with new symptoms of multiple sclerosis that are prevented by disease modifying therapies. Mult Scler Relat Disord. 2021;52:102939.

10. Thompson EJ, Williams DM, Walker AJ, et al. Risk factors for long COVID: analyses of 10 longitudinal studies and electronic health records in the UK. medRxiv. 2021. 06.24.21259277; doi: https://doi.org/10.1101/2021.06.24.21259277 


\section{Neurology $^{\odot}$ \\ Neuroimmunology \& Neuroinflammation}

\section{Recovery From COVID-19 in Multiple Sclerosis: A Prospective and Longitudinal Cohort Study of the United Kingdom Multiple Sclerosis Register \\ Afagh Garjani, Rodden M. Middleton, Richard Nicholas, et al. \\ Neurol Neuroimmunol Neuroinflamm 2022;9; \\ DOI 10.1212/NXI.0000000000001118}

This information is current as of November 30, 2021

\section{Updated Information \& \\ Services}

References

Subspecialty Collections

Permissions \& Licensing

Reprints including high resolution figures, can be found at: http://nn.neurology.org/content/9/1/e1118.full.html

This article cites 8 articles, 0 of which you can access for free at: http://nn.neurology.org/content/9/1/e1118.full.html\#\#ref-list-1

This article, along with others on similar topics, appears in the following collection(s):

All Psychiatric disorders

http://nn.neurology.org//cgi/collection/all_psychiatric_disorders COVID-19

http://nn.neurology.org//cgi/collection/covid_19

Disability

http://nn.neurology.org//cgi/collection/disability

Multiple sclerosis

http://nn.neurology.org//cgi/collection/multiple_sclerosis

Information about reproducing this article in parts (figures,tables) or in its entirety can be found online at:

http://nn.neurology.org/misc/about.xhtml\#permissions

Information about ordering reprints can be found online:

http://nn.neurology.org/misc/addir.xhtml\#reprintsus

Neurol Neuroimmunol Neuroinflamm is an official journal of the American Academy of Neurology.

Published since April 2014, it is an open-access, online-only, continuous publication journal. Copyright

Copyright $\odot 2021$ The Author(s). Published by Wolters Kluwer Health, Inc. on behalf of the American

Academy of Neurology.. All rights reserved. Online ISSN: 2332-7812.

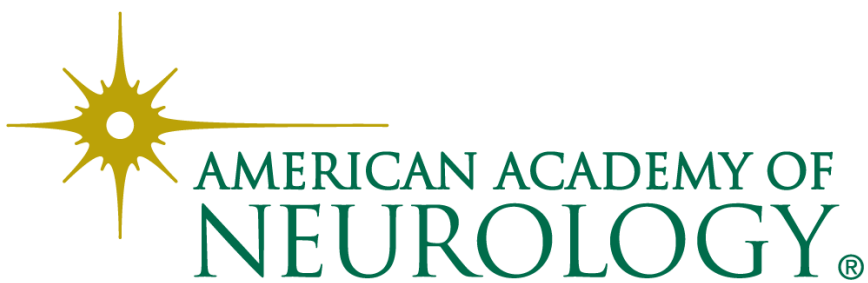

